\title{
ÉTICA E ENSINO SUPERIOR EM DESIGN
}

\section{Ethics and higher education in design}

\author{
Deborah Camila Viana Cardoso \\ Mestranda em Design pela Universidade do Estado de Minas Gerais (UEMG) - \\ deborahcvcardoso@gmail.com - orcid.org/0000-0002-5884-157X \\ Edson José Carpintero Rezende \\ Doutor em Ciências da Saúde pela Faculdade de Medicina da Universidade Federal de Minas Gerais (UFMG)- \\ edson.carpintero@gmail.com - orcid.org/0000-0003-0692-0708
}

\section{Resumo}

O design pertence ao campo das ciências sociais aplicadas e, por isso, aceita contribuições de diversas áreas para compor a matriz curricular da graduação. Isso, porém, muitas vezes contribui para a fragmentação do saber no ensino do design, sob o nome, muito usual, de interdisciplinaridade. Atualmente, as faculdades de design no Brasil se firmam como produtoras de conhecimento, mas ainda mantêm o foco no "ensinar a fazer". É o que se verifica em disciplinas de prática projetual, muitas vezes sem embasamento teórico-científico e, principalmente, distantes do usuário real e da realidade social que cerca a universidade. Ignoram-se as finalidades do ensino superior e seus deveres em relação à sociedade, determinados em leis específicas, como a lei de Diretrizes e Bases da Educação Nacional - LDB - lei $n^{\circ}$ 9.394/1996. Com base nesses questionamentos e com foco na ética no ensino superior em design, construiu-se este artigo utilizando-se da revisão da literatura e da descrição de uma experiência em sala de aula, com o objetivo de questionar e avaliar a prática docente em uma faculdade de design e o papel do professor de design nos processos de ensino-aprendizagem. Concluiu-se que esses processos são uma realidade complexa e que estudos nesta área merecem desdobramentos.

Palavras-chave: Ética. Design-Estudo e ensino. Educação moral (Superior).

\begin{abstract}
The design belongs to the field of applied social sciences and, therefore, accepts contributions from several areas to compose the graduation programmes. This, however, often contributes to the fragmentation of knowledge in the teaching of design, under the very usual name of interdisciplinarity. Today, design colleges in Brazil try to establish themselves as knowledge producers, but still focus on "teaching to do." This is what happens in disciplines of projectual practice, often without a theoretical-scientific base and, mainly, distant from the real user and the social reality surrounding the university. The objectives of higher education and its duties towards society, as determined by specific laws, such as the Law of Directives and Bases of National Education - Law Number 9,394/1996, are ignored. Based on these questions and with a focus on ethics in higher education in design, this article was constructed using the literature review and the description of a classroom experience, with the objective of questioning and evaluating the teaching practice in a faculty of design and the role of the design teacher in the teaching-learning processes. It was concluded that these processes represents a complex reality and that studies in this area deserve unfolding.
\end{abstract}

Keywords: Ethic. Design-Study and teaching. Moral education (Higher)

Recebido em:10/03/2019

Aceito em: 06/04/2020 


\section{INTRODUÇÃO}

O Design consiste em "um processo estratégico de resolução de problemas que impulsiona a inovação, constrói o sucesso do negócio e leva a uma melhor qualidade de vida através de produtos, sistemas, serviços e experiências inovadores" (WDO,2015). Mais do que isso, para Maiocchi e Pillan (2013), design é comunicação e, para Lana (2011) ele tem se aproximado cada vez mais da origem literal do termo - "Designo" - que significa intento, intenção, propósito e "isso requer além de técnica e talento, uma nova habilidade do designer: a gestão de sistemas complexos; o designer produzindo para as pessoas, ou seja, o primeiro sistema complexo produzindo para o segundo" (LANA, 2011, p. 59). O design, por consequência, tem sido cada vez mais focado no ser humano e, por isso, maior é a necessidade de ouvir, observar, encontrar, conversar com os clientes/usuários para planejar ações e intervenções.

O usuário, portanto, é o centro das ações de design e, por esse motivo, é impossível pensar o ensino do Design desassociado de práticas projetuais com foco em usuários reais e em contextos igualmente verdadeiros. Diante dessa realidade, percebe-se que pensar o ensino nos cursos de graduação, em especial nos cursos de design, relacionando-o ao usuário real, seria a condição para se obter um ensino superior de qualidade, proporcionando ao aluno contato com usuários reais para os quais se projetasse, além de oferecer, para a sociedade, um serviço que os beneficiaria e transformaria de forma positiva.

A fragmentação do conhecimento, característica da contemporaneidade, também é um fator dificultador do ensino em Design. Como pertencente ao campo das ciências sociais aplicadas, que aceita contribuições de diversas áreas do saber, o Design deve superar o desafio da interdisciplinaridade encarada como conhecimento de várias áreas, sem o devido entendimento e a conexão entre os saberes que possibilite aplicação prática-profissional do objeto estudado, uma vez que a interdisciplinaridade se caracteriza justamente pela conexão entre saberes e culturas diferentes.

O processo de ensino-aprendizagem, muito estudado pela pedagogia, não é mais considerado resultado de ações isoladas do professor e dos alunos, mas sim um processo coordenado e integrado a tal ponto que não se considera ensino quando uma aprendizagem efetiva não é alcançada. Este artigo foi desenvolvido utilizando-se da revisão narrativa da literatura, entendida esta como a investigação da posição de diversos autores sobre o tema abordado em seus aspectos subjetivos e 
qualitativos, de maneira a explorar, de forma imparcial e ampla, o assunto em questão. Como objetivo deste trabalho, considerou-se o papel do professor no processo de ensino-aprendizagem e traçou-se um paralelo com o que ocorre no ensino superior em design, relacionando com a ética no exercício profissional do professor dos cursos de design e com o papel social da universidade, a fim de avaliar-se a prática docente e o processo de ensino-aprendizagem nas faculdades de design.

\section{FUNDAMENTAÇÃO TEÓRICA}

\subsection{CONTEXTO HISTÓRICO DO ENSINO SUPERIOR NO BRASIL}

A constituição da República Federativa do Brasil de 1988 - CR/88 - determina em seu art. 207:

Art. 207. As universidades gozam de autonomia didático-científica, administrativa e de gestão financeira anata patrimonial, e obedecerão ao princípio da indissociabilidade entre ensino, pesquisa e extensão (BRASIL, 1988).

Até as universidades chegarem a esse patamar de autonomia, um longo caminho foi percorrido, o que remonta à história do ensino superior no Brasil, que foi iniciada com a vinda da Corte Portuguesa, em 1808, e a criação de cursos que atendessem a necessidade da própria corte, dentre eles, o de Desenho Técnico, em 1818. Após a proclamação da República, novas faculdades foram surgindo também de forma isolada, até a formação da primeira universidade no Rio de Janeiro, em 1920. A partir da década de 1930, depois da criação do Ministério da Educação, houve tendência de federalização do ensino superior, como exemplo das seguintes universidades: a USP (Universidade de São Paulo), em 1934; a UDF (Universidade do Distrito Federal), em 1935; a UFRGS (Universidade Federal do Rio Grande do Sul), em 1947; a UFMG (Universidade Federal de Minas Gerais), em 1949; a UFBA (Universidade Federal da Bahia), em 1946, estendendo-se pelas décadas de 1960 e 1970 o processo de criação das universidades federais, de modo geral nas capitais dos estados (SAVIANI, 2011). Com isso, pode-se perceber que, no Brasil prevaleceu por longo período o modelo napoleônico de ensino, quando havia muita ingerência do Estado na Educação, além de outros aspectos ideológicos marcados pela influência francesa: a laicidade, a predominância das ciências humanas. "A tradição francesa era liberal e humanista e foi esta a mais forte influência na formação da universidade brasileira" (LUCCHESI, 2011). Somente em 1988, com o advento da Constituição, que se incorporaram várias das reivindicações da população relativas ao ensino superior no seu texto. 
Consagrou-se assim a autonomia universitária, estabeleceu-se a indissociabilidade entre ensino pesquisa e extensão, garantiu-se a gratuidade nos estabelecimentos oficiais; assegurou-se o ingresso por concurso público e o regime jurídico único. Após isso, a luta foi no sentido de se conseguir dotação orçamentária que viabilizasse o exercício da autonomia didático-científica, administrativa e de gestão financeira e patrimonial de que trata o art. 207, já citado, da CR/88 (BRASIL, 1988).

O que se observou, porém, é que essas universidades públicas criadas não foram suficientes para atender a demanda da população por vagas no ensino superior. Por isso, a partir da década de 1980, houve uma expansão do ensino superior. Criaram-se, para isso, em 1986, a distinção entre "Universidades de Pesquisa" e "Universidades de Ensino", culminando, nos termos atuais, na distinção entre Universidades e Centros universitários, sendo que esses últimos não realizam pesquisa e extensão, se tornando um eufemismo das universidades de ensino, caracterizados pela democratização da universidade a baixo custo, como alternativa para viabilizar essa expansão (SAVIANI, 2011).

Com isso, houve maior necessidade de serem os centros universitários voltados para o mercado de trabalho e de menor custo ao consumidor, uma espécie de incorporação do modelo anglo-saxônico e prussiano ao modelo brasileiro de universidade, que era o napoleônico - francês. Onde prevalecia o Estado, aos poucos houve grande influência da sociedade civil na demanda por mais vagas e pela democratização do ensino (modelo anglo-saxônico) e pressão da própria universidade por maior autonomia da comunidade acadêmica frente ao Estado e a sociedade civil (modelo prussiano ou "humboldtiano") (SAVIANI, 2009). O fato é que para ser classificada como universidade, a instituição deve estar ancorada em três pilares: ensino, pesquisa e extensão, e desenvolver os três, com igual intensidade, para garantir um ensino de qualidade (BRASIL, 2018).

\subsection{A EXPERIÊNCIA COMO BASE DE UM ENSINO SUPERIOR DE QUALIDADE}

Naves (2015) recorre, em seu texto, a autores que fundamentam a importância da experiência como produtora de conhecimentos, veja-se: a autora afirma que a experiência prática e social não é um exercício exclusivo da extensão universitária, mas o ensino também faz uso de atividades práticas para produzir conhecimento. 
A Lei de Diretrizes e Bases da Educação Nacional (LDB - Lei no 9.394/1996) reforça a função da universidade quando em seu art. 43 determina as finalidades da educação superior no Brasil, dentre elas as citadas nos incisos IV e VI, a saber:

IV - promover a divulgação de conhecimentos culturais, científicos e técnicos que constituem patrimônio da humanidade e comunicar o saber através do ensino, de publicações ou de outras formas de comunicação;

[...]

$\mathrm{VI}$-estimular o conhecimento dos problemas do mundo presente, em particular os nacionais e regionais, prestar serviços especializados à comunidade e estabelecer com esta uma relação de reciprocidade. (BRASIL, 1996 - grifo nosso)

Pensar o ensino, portanto, não é pensar apenas o compromisso social da universidade, mas pensar, também, a relação da universidade e da sociedade de forma dialógica, onde a experiência social proporcione a junção entre o saber (teórico) e o fazer (prático), solucionando em grande parte as reclamações dos alunos no que diz respeito ao distanciamento dos cursos de graduação da realidade prática de mercado que os espera ao fim da graduação. Nesse contexto, há formação de pessoas e geração de conhecimento, sendo o aluno protagonista de sua formação técnica para obtenção de competências necessárias à sua formação profissional. Baseada no pensamento de Boaventura de Souza Santos, Naves (2015) ressalta que está havendo um "desperdício da experiência" no atual modelo de universidade e que o conhecimento emancipatório depende da relação do pesquisador com o mundo. Tudo que for contrário a isso, contribui para minorar a qualidade do saber gerado no meio acadêmico, uma vez que trata o ser humano e seus contextos de forma objetificada e empobrecida, "fechando-se para saberes e desvalorizando a experiência", ou seja, distanciando-se da vida e problemas sociais reais (NAVES, 2015, p. 20).

\section{3 ÉTICA, ENSINO SUPERIOR E DESIGN: ESTÍMULO A COMPORTAMENTOS ÉTICOS}

Chauí (1995, p. 341), ao discutir sobre a moral e a ética em Sócrates e Aristóteles, afirma que o primeiro definiu o que seria um sujeito ético moral como sendo aquele que "sabe o que faz, conhece as causas e os fins de sua ação, o significado de suas intenções e de suas atitudes e a essência dos valores morais"; o segundo acrescentou à referida consciência do agente moral, pensada por Sócrates, a ideia da vontade guiada pela razão como segundo elemento da vida ética, uma vez que há situações sobre as quais não se delibera, como as estações do ano, o movimento dos astros ou eventos da natureza, mas há também situações às quais dependem de deliberação e escolhas humanas para que possam acontecer, e nesse campo de ação se encontra a ética. 
A ética e a moral, por definição, são conceitos que se interpenetram, mas não se confundem. Cordi et al. (2001, p. 61) definem moral como sendo "um conjunto de normas, prescrições e valores que regulamentam o comportamento dos indivíduos na sociedade". A norma moral se distingue da norma jurídica, por exemplo, que também regula comportamentos sociais, pelo fato de ser anterior a ela e advir de uma coação interna, da consciência, e não de uma coação externa, do Estado. E a ética, ou filosofia moral, por sua vez, seria "uma reflexão sistemática sobre o comportamento moral. Ela investiga, analisa e explica a moral de uma determinada sociedade" (CORDI et al., 2001, p. 63). Por esse motivo, a pergunta "isso é certo?" é mais importante que a "isso é legal?", uma vez que se pode agir usando uma lei para violar princípios que o sistema jurídico como um todo deseja proteger, por exemplo. Por isso, os princípios são maiores que as leis e, portanto, a base da ética (EPLEY; TANNENBAUM, 2007).

A moral, então, varia de cultura para cultura e possui, portanto, certo relativismo (CORDI et al., 2001). A prova disso é que antropólogos, com frequência, têm documentado diferenças entre culturas (FRIEDMAN; KAHN, 2003). Chauí (1995, p. 347), ao analisar Hegel e Kant, afirma que somos seres históricos e culturais, o que significa que, "além de nossa vontade individual subjetiva [...], existe outra vontade, muito mais poderosa, que determina a nossa: a vontade objetiva, inscrita nas instituições ou na cultura". Conclui daí que a vida ética somente é possível quando há uma harmonia entre a vontade individual subjetiva e a vontade cultural objetiva.

Rocha e Correia (2006, p. 1-2) definem ética como "a ciência do comportamento moral dos homens em sociedade", cuja função é "levar a sociedade a reagir, resgatando valores morais básicos para orientação de seu comportamento e, assim, empreender um caminho de reconstrução para uma vida melhor". Logo, a função da ética é levar o homem a agir com virtudes que, conforme Chauí (1995, p. 342) são uma força interior do caráter, que consiste "na consciência do bem e na conduta definida pela vontade guiada pela razão, pois cabe a esta última o controle sobre instintos e impulsos irracionais descontrolados que existem na natureza de todo ser humano".

Quando se fala em ética na docência pode-se compreendê-la sob alguns aspectos: o primeiro é aquele que proporciona um "ensino para a vida", diferente do conhecimento desvencilhado de qualquer relação com a realidade, do qual o aluno raramente extrai proveito para sua subsistência. O segundo é o fomento do conhecimento que incentive no aluno a busca por um comportamento mais humano e por uma sociedade mais justa (ROCHA; CORREIA, 2006). Isso se torna possível ao se 
manter a ética no "top of mind" dos alunos, ou seja, já se identificou que as decisões humanas normalmente são tomadas baseadas nas informações que estão mais acessíveis àquele tempo. Se os educadores, portanto, tratarem de temas éticos de maneira frequente em sala de aula, os alunos rotineiramente serão levados a pensar sobre ela, o que levará o tema a ser sempre acessível à mente daquele que precisa tomar uma decisão profissional. A motivação ética que os alunos recebem também se torna responsável por encorajar comportamentos éticos. Importante ressaltar que falar sobre ética é diferente de falar da "falta dela": este tipo de abordagem do tema tem se mostrado destrutivo sob o ponto de vista motivacional e tem apresentado poucos resultados efetivos (EPLEY; TANNENBAUM, 2007). O trabalho do professor também é avaliado quanto ao seu planejamento, seu desenvolvimento e seus resultados, de forma que Rocha e Correia (2006) afirmam que uma aula não é apenas um movimento de ideias. Ela é ato de criação e expressão de valores científicos, estéticos e éticos do professor, dos alunos e da própria cultura. Logo, o trabalho docente ético é aquele realizado conforme o planejado, cujos resultados oferecem benefícios para o docente, mas também para toda a sociedade, visto que esses profissionais atuarão no mercado e influenciarão o mecanismo de organização social. Um forte mecanismo que possivelmente possibilitará ao aluno uma trilha ética no exercício profissional é a sua capacidade de reflexão, comumente trabalhada em salas de aula no nível superior de ensino.

Quando o assunto é design e projeto, necessário é oferecer métodos de design que respeitem a cultura e o contexto daqueles para quem se projeta (FRIEDMAN; KAHN, 2003), o que somente é possível ao manter uma aproximação entre a academia e a vida prática. Mais que isso, projetar um sistema ético é fazê-lo de maneira que a ética esteja em primeiro plano e seja tema central para o enquadramento de políticas e iniciativas e que aumente a motivação social no agir ético de quem o acessa ou entra em relação com ele (EPLEY; TANNENBAUM, 2007).

\subsection{ENSINO-APRENDIZAGEM: MODELOS DE ENSINO, INTERDISCIPLINARIDADE E FRAGMENTAÇÃO DO SABER NO ENSINO SUPERIOR EM DESIGN}

Além da questão do distanciamento do ensino universitário da vida prática, Couto (2011) traz à tona outro problema vivenciado, atualmente, na era da informação: a fragmentação do conhecimento. Ela trata do tema quando discute a educação superior no Brasil e a forma como está, na maior parte das vezes, organizada: em um modelo linear e fragmentador de conhecimento, como 
se o conhecimento fosse passível de ser dividido em segmentos. E ressalta ainda que, fora da universidade, quando o objetivo não é gerar conhecimentos, mas resolver problemas práticos, não existe essa demarcação e delimitação de áreas, o que possibilita o trabalho em conjunto e a troca de conhecimentos entre pessoas de diversas áreas do saber. Essa troca de experiências deveria ser proporcionada e vivenciada dentro da própria universidade, como forma de preparar o aluno de graduação para o mercado de trabalho. Portugal e Couto (2010), em artigo que analisa o Design em situações de ensino-aprendizagem, ressaltam que "os problemas que atingem a humanidade atual devem ser resolvidos de uma maneira sistêmica, ao contrário dos enfoques fragmentados que caracterizam nossas instituições educacionais" e que a importância da experiência não pode ser relegada a segundo plano, pois, "tudo que construímos e organizamos é na realidade uma experiência" (PORTUGAL; COUTO, 2010, p. 5). Escolas com organizações burocráticas e estruturas hierarquizadas, então, distanciam a instituição de ensino das necessidades dos alunos. Afirmam as autoras que as transformações pelas quais a educação está passando pressupõe uma compreensão mais holística, global e sistêmica do mundo e que, por isso, a interatividade, a interdependência e a interconectividade devem ser pensadas como forma de enfatizar o todo ao invés das partes de um problema.

Celaschi e Moraes (2013), ao analisarem os modelos contemporâneos de ensino em design, ressaltam que as faculdades de design ainda não se adaptaram à quebra do paradigma racionalfuncionalista no ensino, que pregava ser possível um modelo exato e preciso de resposta para os problemas projetuais, o que os autores chamam one best way. Muitas vezes as respostas às questões formuladas pelos estudantes de design não são objetivas e passam por disciplinas da área humanista que tem mais ou menos aproximação com o design: antropologia, sociologia, história, psicologia etc. Já na década de 1970, pensando sobre o assunto do ensino, Redig definiu as disciplinas que deveriam ser base para o ensino do Design no Brasil, quais sejam, antropologia, percepção, ergonomia, economia, tecnologia, ecologia (BARCELLOS et al., 2015). Todas estudadas através de suas metodologias. O design, como área do conhecimento interdisciplinar por definição (WDO, 2015), comporta contribuições de todas elas. Afirmam ainda Celaschi e Moraes (2013) que muitas escolas estão tendo dificuldades de compreender essa mudança que está ocorrendo na educação. Os estudantes, para completar sua formação, têm se valido de outras experiências que não passam pelos bancos escolares, incluindo visitas a museus de arte, filmes cult, músicas experimentais, viagens 
para destinos exóticos. Isto "não apresenta nenhum demérito à academia, que deve justamente contar com essa nova realidade que se prefigura como modelo de autogestão do conhecimento em cenário de complexidade estabelecido", uma vez que todas as experiências de vida somadas é que compõem a formação do saber pessoal. Isso, contudo, não diminui a responsabilidade das faculdades pelo zelo por um ensino superior de qualidade (CELASCHI; MORAES, 2013, p. 39).

O design, portanto, não poderia estar fora desse contexto de experiência, pois o foco de seu trabalho e seu motivo de ser são as pessoas e, para elas, individualizadas ou coletivamente, é que se desenvolvem trabalhos de design. Maiocchi e Pillan (2013) quando definem o design como uma "capacidade de comunicar emoções", salientam que o artefato de design deve conter ao menos três componentes: a função, que é o objetivo do produto; a forma, que diz respeito à sua aparência; e seu significado, que é a interpretação comunicada. Com base nisso, criaram um modelo adequado para a atividade do design (FIGURA 1), que relacionava todos os sinais, percepções e emoções que o usuário deve receber para conseguir interpretar o artefato conforme os objetivos de projeto, demonstrando a complexidade da comunicação em um contexto de design, mas representando também o usuário no centro do processo.

Figura 1: Modelo adequado para a atividade do design segundo Maiocchi e Pillan (2013)

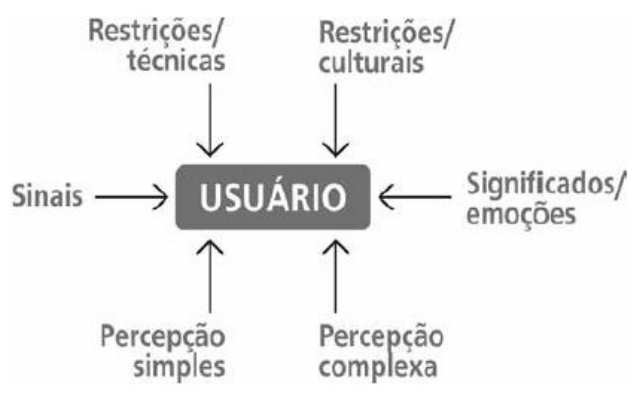

Fonte: Maiocchi e Pillan (2013, p. 29).

Qualquer universidade, portanto, que mantenha uma matriz curricular específica para ensino do design em sua graduação e que despreze a importância da relação com o usuário na formação deste profissional, está desvalorizando a própria profissão e o pensar sobre o design, que está cada vez mais centrado no ser humano. (GARCEZ; RIBEIRO; PEREIRA, 2016). Walter Benjamim (2012) afirma que os homens passaram a viver uma nova miséria a partir do momento em que se desenvolveu a técnica, mas ela foi desvinculada do patrimônio cultural e da experiência das pessoas. 
Naves (2015), ao analisar essa fala de Benjamim (2012), propõe algumas reflexões, que devem ser consideradas: "Qual o sentido da minimização do valor da experiência? Existe uma relação de pertinência entre o fazer e o saber que proporcione a construção de conhecimentos com valor emancipatório? [...]" E continua: "O que o aluno está fazendo quando participa de uma atividade de campo? Em que medida a construção de conhecimentos, alicerçada na prática, contribui para a aplicação desses conhecimentos com possibilidades de transformação, tanto do sujeito, quanto da sociedade?" (NAVES, 2015, p. 11). Percebe-se, a partir destas reflexões, que a experiência prática deve ser considerada como um fator agregador entre prática e teoria que seria interessante se pensada dentro do ensino, uma vez que a atuação do formando no mercado deverá se dar dentro de um sistema cultural-moral posto, ao qual pode-se, obviamente, ser questionado por meio da filosofia moral ou ética, mas que não prescinde de ser conhecido, mesmo para que mudanças em sua estrutura possam ser propostas.

A experiência prática no ensino superior em design, portanto, não pode ser desconsiderada, pois desenvolve habilidades técnicas, mas também as humanidades, dentre elas, a empatia! Empatia é a capacidade de nos colocarmos no lugar no outro e, no caso do Design, essencial para que se entenda o problema projetual. Compreender o conceito de empatia é imprescindível quando se pensa em ética, uma vez que esta apenas existe quando analisada sob o ponto de vista social e da interrelação humana, inserida em um contexto cultural (CHAUÍ, 1995). Mayernyik e Oliveira (2016, p. 13) definem empatia como a "a centelha de preocupação humana com os outros, a cola que torna a vida social possível" e afirmam também que a "educação moral pode conduzir-nos a uma preocupação empática pela pessoa ou grupos de pessoas que não conhecemos muito bem ou que em absoluto não conhecemos", compreensão necessária ao desenvolvimento de projetos de design que mantenham as necessidades dos usuários no centro de suas preocupações para soluções projetuais.

Uma vertente metodológica do Design que tem na empatia um dos seus pilares, por exemplo, é o Design Thinking. Conforme Bonini e Sbragia (2011), o Design Thinking costuma ser dividido em três fases: a inspiração, a ideação e a implementação. Na primeira fase formulam-se questões para entender o real problema do cliente. Para isso, métodos da etnografia são utilizados, dentre eles a observação participante, na qual se pressupõe, sobretudo, empatia. Caso não haja empatia nessa fase, haverá o problema do olhar e ouvir viciado pelo ponto de vista do pesquisador, 
conforme explica melhor Oliveira (2000) em sua obra "O trabalho do Antropólogo", quando trata do trabalho de campo na antropologia. A realidade que pode facilmente ser apropriada pelos designers, visto que a maioria de seus trabalhos depende de uma vivência prática e do entendimento de uma realidade social e pessoal vigente para poderem projetar.

Garcez, Ribeiro e Pereira (2016, p. 1.466) salientam ainda que, normalmente, nas disciplinas de prática projetual a "experimentação da metodologia de projeto acontece por meio de um problema simulado para a tarefa do aprender, possibilitando aos alunos construírem e experimentarem um mapa do caminho que devem traçar para solucionarem o problema simulado". Ainda conforme os autores, o ensino de Design deve propor uma abordagem prática reflexiva com a existência de disciplinas orientadas para o ofício e, por isso, "a adoção da realidade, e não a sua simulação, pode ser um recurso que favoreça esse processo reflexivo, por partir de fatos e dados reais" (p. 1.466). Quando as metodologias utilizadas no fazer-design são centradas no usuário, há uma relação mais estreita entre usuários e designers, pois a construção efetiva do design, quando centrada no usuário, leva em conta suas necessidades e interesses (KULPA; PINHEIRO; SILVA, 2011). Nesse sentido, as metodologias empregadas nos processos de design não devem acontecer em etapas tão lineares e deve ocorrer maior interação entre as pessoas envolvidas durante as etapas do projeto, e não apenas no seu início e fim, em uma lógica meta projetual (MORAES, 2011). É importante, portanto, incluir a presença do usuário real na prática projetual no meio acadêmico, nos seus exercícios de projetos na graduação, pois assim os alunos passariam a desenvolver projetos a partir de universos reais e a aprovação dos mesmos não dependeria apenas de um professor, mas de alguém que está diretamente relacionado ao contexto para o qual se projeta. O usuário, então, a partir dessa relação, contribuiria para que o ensino se concretizasse de forma mais eficiente, pois há um briefing real e não um previamente idealizado por um professor e entregue aos alunos (GARCEZ; RIBEIRO; PEREIRA, 2016).

Nesse ponto pode-se abordar a questão do ensino-aprendizagem conforme é difundida nas disciplinas de didática. O ensino e a aprendizagem estão de tal modo associados que não se separa mais um do outro, sendo chamados por alguns autores de "ensino-aprendizagem" (KUBO; BOTOMÉ, 2001) ou, por outros, defensores enérgicos de sua indissociabilidade, de "ensinagem" (ANASTASIOU; ALVES, 2007). Fato é que o processo de ensino-aprendizagem envolve dois verbos: ensinar: que é "o 
que faz o professor"; e aprender: que é "o que acontece com o aluno em decorrência desse fazer do professor" (KUBO; BOTOMÉ, 2001, p. 5).

Ninguém pode afirmar que "ensinou, mas o aluno não aprendeu". Ensinar define-se por obter aprendizagem do aluno e não pela intenção (ou objetivo) do professor ou por uma descrição do que ele faz em sala de aula. A relação entre o que o professor faz e a efetiva aprendizagem do aluno é o que, mais apropriadamente, pode ser chamado de ensinar (KUBO; BOTOMÉ, 2001, p.5).

Do ponto de vista da ética no exercício profissional, enquanto professor deve-se buscar meios de ensinar e modificá-los até que se atinja o objetivo proposto para a disciplina, pois não pode ser considerada ética a atitude de ensinar sabendo que ninguém está aprendendo. A lei de diretrizes e bases da Educação nacional (lei no 9.394/1996) estabelece em seu art. 13, inciso II, que é dever dos docentes zelar pela aprendizagem dos alunos e completa, no inciso IV, que devem também estabelecer estratégias para recuperar aqueles alunos com menor rendimento (BRASIL, 1996). A aprendizagem, portanto, é decorrente em grande parte da conduta do professor, que deve agir como um educador, um mediador, e não se portar como o único detentor do conhecimento. No processo de ensino-aprendizagem, a aprendizagem é mútua e decorre do fato de professores e alunos estarem abertos a novas informações e experiências, demonstrarem empatia e respeito no ambiente acadêmico (KUBO; BOTOMÉ, 2001; BRAIT et al., 2010; VASCONCELOS; PRAIA; ALMEIDA, 2003).

A educação está inserida no processo contemporâneo, dinâmico, de complexidade e não se pode esperar do aluno que ele continue aprendendo com a utilização e repetição de velhos métodos ineficazes e desinteressantes de ensino. Também não se deve esperar dos professores que eles repitam os mesmos métodos usados desde sempre. Os alunos chegam à sala de aula trazendo cada vez mais experiências diversificadas de suas histórias de vida e é necessário considerá-las na organização do plano político pedagógico da instituição de ensino a que estão vinculados. O professor deve operacionalizar essa política com seu trabalho docente, organizando-o por meio da elaboração e execução dos planos de ensino e planos de aula (ANASTASIOU; ALVES, 2007). É nesse contexto de trabalho do professor que se inserem as estratégias de ensino-aprendizagem, que utilizam cada vez mais metodologias ativas na educação, fazendo com que o aluno deixe de ser sujeito passivo e passe a tomar as rédeas do seu aprendizado, participando verdadeiramente do processo de ensinoaprendizagem. Afirma Morán (2015) que as metodologias devem acompanhar os objetivos pretendidos para o ensino de determinada disciplina. Se se deseja que os alunos sejam proativos, 
devem-se adotar metodologias pertinentes, que envolvam raciocínios complexos, tomadas de decisão e análise de resultados. Da mesma forma, se se quer que sejam criativos, eles devem ter a oportunidade de demonstrar sua criatividade por meio das várias respostas possíveis a uma dada situação problema. Para Akinoglu e Tandogan (2007), processos ativos de aprendizagem não são padronizados, mas se transformam em uma forma personalizada de aprender, pois cada um deve desenvolver o processo da forma que ache mais eficaz para o seu caso em particular e entender o grau de responsabilidade que tem sobre seu próprio aprendizado.

Para citar algumas dessas estratégias ou metodologias ativas para o ensinoaprendizagem, com base no texto de Anastasiou e Alves (2007), tem-se: a aula expositiva dialogada, o estudo de texto; o uso do portfólio, da tempestade cerebral, do mapa conceitual; o estudo dirigido, a lista de discussão por meios informatizados, os grupos de verbalização e de observação, a dramatização, a apresentação de seminários, os estudos de caso, os simpósios, fóruns, oficinas, laboratórios e workshops, o ensino com pesquisa, e, por último, duas metodologias que, além de todas as citadas, interessam muito especificamente ao ensino superior do design, que é a aprendizagem baseada na solução de problemas e a aprendizagem baseada em projetos.

A aprendizagem baseada em problemas é uma metodologia consistente no enfrentamento de uma situação nova, "exigindo pensamento reflexivo, crítico e criativo a partir dos dados expressos na descrição do problema; exige a aplicação de princípios, leis que podem ou não ser expressos em fórmulas matemáticas" (ANASTASIOU; ALVES, 2007, p. 29). Esse tipo de estratégia teve sua origem no ensino praticado em disciplinas da área da saúde, mais especificamente em algumas escolas de medicina, que têm uma filosofia pedagógica de aprendizado centrada no aluno e não no professor. Nesse caso, um problema é proposto com o objetivo de que o aluno estude determinados conteúdos em profundidade, que desenvolva habilidades sociais de comunicação, trabalho em equipe, de gerenciamento de tempo e recursos, que busque ativamente alguns conhecimentos específicos, e que não se transforme em uma prática meramente informativa, como nas práticas educacionais tradicionais. Nesse caso, o estudante "aprende a aprender" (AKINOGLU; TANDOGAN, 2007; BERBEL, 1998; BORGES et al., 2014). A situação-problema apresentada, deve, pois, se aproximar de uma ocorrência real, com a qual os alunos terão contato durante o exercício profissional, uma espécie de antecipação vivenciada durante o curso de graduação, para prepará-lo para a realidade prática e fazê-lo pensar, refletir e investigar para encontrar soluções. 
(BOROCHOVICIUS; TORTELLA, 2014; MORÁN, 2015) A aprendizagem acontece em pequenos grupos e o professor exerce papel de mentor, orientando e direcionando os alunos para o melhor aproveitamento do processo. O mentor é uma espécie de guia que tem o papel de "monitorar discussões, fazer perguntas, auxiliar na resolução de ocasionais conflitos, permitir a participação de cada membro do grupo nas discussões em sala de aula, dar exemplos quando solicitado, prevenir a dispersão nas discussões e fazer avaliações" (AKNOGLU; TANDOGAN, 2006, p. 72).

A aprendizagem baseada em projetos é bastante similar à anteriormente abordada, baseada em problemas, e pode ser definida "pela utilização de projetos autênticos e realistas, baseados em uma questão, tarefa ou problema altamente motivador e envolvente, para ensinar conteúdos acadêmicos aos alunos no contexto do trabalho cooperativo" (BENDER, 2014, p.15). Para De Los Rios et. al. (2010) é a metodologia educacional adequada para desenvolvimento de competências como o gosto por ensinar de forma profissional, além de ajudar os estudantes a trabalhar em equipes, potencializar sua personalidade e fazê-los trabalhar mais próximos à realidade. Há ainda o incentivo à investigação, inovação e criatividade quando se usa essa metodologia ativa de aprendizagem. Trabalha-se por um longo período de tempo para solucionar uma questão, que envolve o estudo de diversos conteúdos, de forma articulada e aplicada. Nesse contexto, o professor orienta o desenvolvimento do trabalho, que, ao contrário da aprendizagem baseada em problemas, pode ser desenvolvido em grandes grupos (NOTAS, 2018).

Esses tipos de metodologias são bastante pertinentes ao ensino superior em design, visto que, na prática, o profissional de design se deparará com problemas projetuais variados, com complexidades diferentes, para os quais deve apresentar soluções criativas, técnicas e objetivas para atender à demanda de um usuário. "O design na atualidade se configura como atividade interdisciplinar, que demanda um olhar holístico e que seja capaz de pensar problemas de um cenário interconectado e complexo (BAHIA et al., 2016, p. 1.281).

As escolas e universidade mais inovadoras, portanto, estão mudando seu modelo de educação baseando-se nessas metodologias ativas de ensino-aprendizagem para proporcionar melhor aproveitamento do aluno em sala de aula, mas isso exige uma "mudança de configuração do currículo, atividades didáticas e da organização de espaços e tempos" (MORÁN, 2015, p. 19), além de uma postura diferenciada dos professores. Eles, porém, têm enfrentado dificuldades nesse sentido e modificar sua prática docente tornou-se verdadeiro desafio. A formação exigida para 
docência no ensino superior tem requerido grande conhecimento prático da atividade a ser ensinada e privilegia, na pós-graduação strictu sensu, onde se deveria desenvolver a capacitação de pessoas para o exercício da docência, a realização de pesquisas, tornando-se ela responsável, mesmo que não intencionalmente, em disseminar essa falsa crença de que, para ser um bom professor, basta ter domínio do conteúdo e ser um bom pesquisador (RIVAS; CONTE; AGUILAR, 2007). Importante ressaltar o quanto são novos os programas de pós-graduação em design no Brasil e o quanto eles têm potencialidade para produzir no sentido de melhorar as fontes de pesquisa e para o ensino do design (NEVES et al., 2014). Os desafios enfrentados pelo docente universitário, portanto, exigem saberes que até então representavam baixo prestígio acadêmico, ou seja, saberes pedagógicos, alicerçados na cultura e na construção da personalidade do professor (CUNHA, 2004). A didática, portanto, área da pedagogia responsável pelo processo de ensino-aprendizagem de forma global, é que seria capaz de fazer essa mediação entre os objetivos do docente e a consciente assimilação de conteúdos por parte dos alunos (LIBÂNEO, 2002).

A ética, nesse contexto de ensino-aprendizagem e formação do professor para o ensino superior em design, residiria no equilíbrio e bom senso em realizar atividades acadêmicas protocolares, exigidas pelo MEC, mas também as atividades criativas, técnicas, humanistas e práticas, como foco em usuários reais, no ensino em design (ANASTASIOU; ALVES, 2007; BAHIA et al., 2016; BRASIL, 1996; GARCEZ; RIBEIRO; PEREIRA, 2016).

\section{DISCUSSÃO}

Sem a finalidade de esgotar o assunto, ele foi abordado e exposto em seminário dentro da disciplina Design e Ética do Programa de Pós-Graduação da Escola de Design da Universidade do Estado de Minas Gerais - PPGD - UEMG.

Seu caráter polêmico proporcionou inúmeras discussões entre os alunos, que, após a exposição, abordaram as seguintes questões.

A academia é local privilegiado para que haja construção do pensamento crítico a respeito de algo e não para se "ensinar a fazer" algo, mecanicamente. A contrapartida a esse ponto de vista se deteve ao fato de que ao se pertencer a uma faculdade de Design, disciplinas técnicas devem existir e andar atreladas às artísticas, criativas e humanistas-sociais. 
A academia não é o lugar adequado para se experimentar o mercado; esse momento seria o estágio curricular obrigatório. Que os alunos deveriam fazer o máximo de estágios possíveis para ter o máximo de experiência e vivência e, de preferência, em locais que trabalhassem com especialidades diferentes. O ponto contrário abordado em relação a isso é que falta mesmo, por parte dos professores, realizarem uma contextualização do ensino do design e a apresentação ao aluno de como aquilo que ele estuda em sala de aula é aplicado de forma prática no mercado de trabalho. E que há, nos estágios obrigatórios, em alguns casos, a deturpação de uma realidade e dos propósitos de estágio, onde os alunos realizam trabalhos mecânicos, sem nenhuma reflexão metodológica ou a respeito do fazer-design, além de não participarem do processo criativo ou de solução de problemas, com o qual se depararão na prática profissional.

As metodologias devem ser usadas para realizar essa contextualização de como o design é aplicado na prática, mas, ao mesmo tempo, várias metodologias, que são estudadas na universidade, não são jamais aplicadas à prática profissional. Então, deveriam mesmo essas metodologias serem estudadas na universidade? Além disso, cada empresa ou escritório acaba por seguir uma metodologia própria. Talvez o ideal não fosse estudar as metodologias de forma generalista e deixar as especificidades para a prática de mercado após o término da graduação?

$\mathrm{Na}$ vida profissional o designer realiza trabalhos multiprofissionais, ou seja, que envolvem profissionais de diversas áreas do conhecimento e que, diferente do que ocorre na academia, nos trabalhos em grupo, que supostamente deveriam desenvolver essa habilidade colaborativa e de relacionamento social, somente se trabalha entre pares, ou seja, com pessoas com a mesma formação ou mesmos interesses. Que a universidade não está formando profissionais capazes de gerenciar essa realidade complexa de interesses. Em oposição a esse ponto de vista houve uma colocação que abordou a necessidade de se ensinar as habilidades que o aluno precisa ter para poder lidar com essa realidade, e que o trabalho em grupo ainda é a melhor forma de fazer isso na faculdade, mesmo que entre pares.

A realidade da formação técnica dos professores não é ruim: é importante que o professor possua saber especializado naquilo que ele ensina. O contrário é que seria ruim: deter o conhecimento didático-pedagógico e não dominar a técnica profissional. No entanto, o ensino da didática é importante para que os professores compreendam não só as metodologias de ensino possíveis no processo de ensino-aprendizagem, mas também a importância dos planos pedagógicos, 
planos de ensino e de aula, instrumentos capazes de contribuir para a organização do ensino de uma disciplina de forma que as atividades consideradas importantes não sejam relegadas a segundo plano ou deixem de ser ensinadas.

Importante lembrar que "na academia pouco se conversa sobre a academia". Não se fala sobre pós-graduação, especialização, mestrado e doutorado. Que durante a graduação, os alunos têm contato com poucos textos e têm uma base teórica em design muito rudimentar para embasar o trabalho projetual. Os alunos de mestrado e doutorado, por esse motivo, também têm pouquíssimas referências do design, e que, tendo de produzir textos e publicações, buscam referências em outras áreas do saber.

Em relação ao processo ensino-aprendizagem é exigido do professor que o aluno de fato aprenda. Se o aluno não aprender é sempre por que o professor não soube ensinar? Ou isso é colocar responsabilidade demais nos ombros dos professores? Os alunos mudaram e, os professores presentes em sala de aula durante esta discussão foram quase unânimes em dizer que têm sentido os alunos muito pouco participativos ou interessados nas propostas diferentes que os professores levam para a sala de aula. Mas será que, tendo o perfil do aluno mudado, a forma de o professor enxergá-lo continua a mesma? Ou ela deve também mudar para se alcançarem resultados mais efetivos?

Alguns alunos salientaram que os professores de design são especializados na aplicação das metodologias ativas da aprendizagem baseada em problemas e em projetos. Outras ressaltaram, porém, que essas metodologias são deturpadas na academia, não porque uma delas exige a aprendizagem em pequenos grupos e que o professor se comporte como tutor daquele grupo, mas porque não se pensa, nas práticas projetuais, nas questões metodológicas, de semiótica, de ergonomia, etc., aplicadas àquele determinado projeto. Ou seja, não há uma reflexão sobre aquele projeto e a sua relação com as disciplinas estudadas na graduação. Dessa forma o saber continua fragmentado, mesmo que se diga o ensino interdisciplinar.

Por fim, a discussão que girou em torno das determinações da LDB (art. 43, VI) no que diz respeito às funções do ensino superior, dentre elas o dever de "prestar serviços especializados à comunidade", estabelecendo com ela uma relação de reciprocidade, se pautou no fato de que, dentro das faculdades de design, no quesito "ensino", pouco se vê sobre esse tipo de interação. Se 
os cursos de design abrissem as portas para a comunidade, já estariam os alunos sendo "treinados" para a prática projetual real.

Outra possibilidade citada em sala de aula, além da do estágio supervisionado, sobre o qual já se comentou, é a participação do aluno em algum projeto de extensão, pois uma pequena comunidade poderia ser considerada uma amostra do mercado; e a formação, dentro da universidade, de uma incubadora de empresas que, vinculada a entidades privadas de apoio ao desenvolvimento de micro e pequenas empresas assim como do empreendedorismo, direcionasse a formação dos alunos para estarem mais preparados para a inserção no mercado de trabalho. Essa preparação em incubação propiciaria a visualização da viabilidade do negócio e o estudo de fatores que são negligenciados em sala de aula, como documentos e procedimentos necessários para o início de um negócio, bem como os impostos que se deve pagar, como se deve determinar e calcular o preço do trabalho ofertado, assim como a realidade do mercado fora da universidade.

Todos esses assuntos discutidos em sala de aula, após a apresentação das questões associadas ao ensino-aprendizagem do design, encontram eco dentro dos temas da revisão da literatura realizada nesse trabalho.

A questão do "ensinar a fazer" que predomina nas faculdades de design foi abordada por Celaschi e Moraes (2013), que afirmam que os modelos de ensino em que essas instituições se firmam ainda estão apegados ao modelo racional-funcionalista que pregava a existência de "one best way" de se fazer algo. A falta de embasamento teórico para os estudos em design também foi tema de Neves et al. (2014), ao discorrer sobre o quanto são recentes os programas de pós-graduação em design no país e o quanto eles têm contribuído para o aumento das publicações e, consequentemente, do suporte teórico para o campo do design. A base para a resposta de muitas questões dentro do design está, algumas vezes, em contato com disciplinas humanísticas (BARCELLOS et al., 2015) que, se estudadas na graduação, são isoladas e não relacionadas com a prática, o que demonstra a falta de conexão entre as disciplinas e, portanto, a falsa interdisciplinaridade pregada no conceito de design da WDO (2015), por exemplo.

Se a interdisciplinaridade é algo ainda rudimentar no ensino do design, observa-se o desejo, no teor das discussões acima, de que ao menos a contextualização do emprego de determinada técnica ensinada em sala de aula seja realizada, para que os alunos entendam a aplicação daquilo no mercado de trabalho, tendo em vista o fato de a prática projetual ser 
normalmente baseada em situações simuladas. Garcez, Ribeiro e Pereira (2016) afirmam que o usuário real dentro da prática projetual em design é essencial para que o ensino seja efetivo, ou seja, que as metodologias de design devem ser empregadas levando em consideração cenários nãosimulados, para que o design centrado no usuário (KULPA; PINHEIRO; SILVA, 2011) possa ser de fato vivenciado. Isso facilita o entendimento da realidade cultural (moral) dentro da qual o designer atuará enquanto profissional para que, por meio de reflexões e questionamentos, possa propor mudanças a esse sistema, caso não esteja de acordo com ele, usando a ética ou filosofia moral (CHAUÍ, 1995).

Se, no campo do ensino, a interdisciplinaridade é algo a que ainda se almeja, na prática no mercado se verifica o trabalho em equipes: profissionais de áreas diversas se reúnem para que, com o conhecimento de cada um, possa ser construída uma solução única e mais adequada ao caso concreto. Portanto, mudar a forma de ensinar talvez seja mais urgente do que se pensa.

As metodologias ativas de aprendizado, no caso específico do design, aquelas em que a aprendizagem é baseada em problemas e em projetos (BENDER, 2014; BORGES et al., 2014; BOROCHEVICIOUS; TORTELLA, 2014; MÓRAN, 2015), são as melhores formas preencher as lacunas deixadas pelos métodos tradicionais de ensino e proporcionar uma conexão entre os saberes fragmentados ensinados na graduação.

A formação didática dos professores é também essencial para que isso ocorra. Mesmo para que eles tenham conhecimento a respeito dos tipos de metodologias de ensino-aprendizagem existentes e poderem decidir a melhor forma de ensinar determinado assunto. A necessidade do domínio técnico do conteúdo a ser ensinado é algo unânime. Pouca importância se dá à formação didática dos professores em cursos de pós-graduação (RIVAS; CONTE; AGUILAR, 2007) que, a princípio, são destinados a formá-los - mestrado e doutorado. E isso tem reflexo diretamente no ensino, na qualidade das aulas que são ofertadas e no grau de aprendizagem do aluno. Ressaltandose, neste ponto, que a real aprendizagem do aluno é dever ético do professor (ANASTASIOU; ALVES, 2007). A falta de planejamento adequado das aulas também espelha o pouco conhecimento sobre didática dos professores. Como visto, um plano de ensino e de aula bem feitos auxiliam o professor a se organizar e passar a mensagem almejada no tempo e com os recursos disponíveis em sala de aula ou fora dela (CUNHA, 2004). A busca por conhecimentos é também dever do aluno, mas é dever do professor tentar aproximá-lo cada vez mais da realidade para que ele seja efetivo e as 
determinações do art. 13, III, da LDB (lei no 9.394/1996) sejam atingidas e o professor tenha, por fim, uma conduta ética ao exercer sua profissão (BRASIL, 1996).

Observa-se também que, na universidade, há a necessidade de teoria e prática andarem juntas, principalmente quando o que está em jogo é a qualidade de cursos de graduação direcionados para formar profissionais que manterão estreita relação com clientes/usuários de serviços de design. As metodologias de ensino-aprendizagem voltadas para o usuário e sua aplicação nas práticas projetuais em design, que hoje tendem a acontecer de forma linear, devem ser repensadas para que proporcionem ao aluno a capacidade de atender às necessidades reais dos clientes em uma situação de trabalho. A falta de articulação entre as disciplinas da graduação, a sua fragmentação, não contribui para a boa formação do designer enquanto profissional e que os desafios da educação superior em design são didáticos e éticos, à medida que a aprendizagem do aluno é mais que um objetivo, mas um dever dos professores, que, normalmente, não são capacitados, didaticamente, para isso.

\section{CONCLUSÃO}

A discussão realizada em sala de aula orbitou ao redor dos seguintes assuntos, quais sejam, funções do ensino superior, deveres dos professores, ética na conduta docente, a fragmentação do conhecimento e a interdisciplinaridade necessária para o ensino-aprendizagem do design, as metodologias ativas de ensino-aprendizagem e a necessidade da didática na formação dos professores, o distanciamento das práticas projetuais da realidade prático-profissional e a falta de embasamento teórico para o campo do design se fortalecer como ciência. Com isso, foram construídas reflexões sobre o ensino-aprendizagem do design e a ética na atividade docente na universidade.

Chegou-se à conclusão de que as situações de ensino-aprendizagem são uma realidade complexa e que ainda demandam muitos estudos, principalmente no campo do design, que é tão carente de referências. Percebeu-se que os professores têm papel fundamental no desenvolvimento do ensino de disciplinas teóricas e práticas, mas, sobretudo, têm o papel de fazê-las efetivas por meio da aproximação entre a realidade prático-profissional e a sala de aula. Eles têm também responsabilidade com a forma pela qual o ensino é direcionado aos alunos, ou seja, o conhecimento das metodologias e a escolha da melhor delas para cada caso de ensino-aprendizagem é que fará a 
diferença entre uma boa aula e uma não tão boa assim. Vale ressaltar, que a ética nos processos de ensino-aprendizagem reside no fato de se verem concretizados os objetivos propostos para cada disciplina e que os alunos, após cursá-las, possam estar aptos a desenvolverem por si mesmos a sua forma de trabalhar e atuar na realidade social em que estarão inseridos como profissionais. A pesquisa, portanto, merece desdobramentos, com a finalidade de contribuir para a melhoria das atividades relacionadas ao ensino nas universidades e ao melhor aproveitamento dos alunos em relação ao conhecimento compartilhado.

\section{REFERÊNCIAS}

AKINOGLU, O.; TANDOGAN, R. O. The effects of problem-based active learning in science education on students' academic achievement, attitude and concept learning. Eurasia Journal of

Mathematics, Science \& Technology Education, Istambul, v. 3, n. 1, p. 71-81, 2007. Disponível em: http://www.ejmste.com/The-Effects-of-Problem-Based-nActive-Learning-in-Science-nEducationon-Students-Academic-nAchievement-Attitude-and-Concept-nLearning,75375,0,2.html. Acesso em: 17 out. 2018.

ANASTASIOU, L. G. C.; ALVES, L. Estratégias de Ensinagem. Florianópolis, 2007. Moodle, UFSC. Disponível em:

https://moodle.ufsc.br/pluginfile.php/1390223/mod_resource/content/1/anastasiou.pdf. Acesso em: 26 jun. 2018.

BAHIA, I. P. et al. "Prática projetual em design de ambientes: relato de experiência sobre a inserção da metodologia aplicada à complexidade". In: CONGRESSO BRASILEIRO DE PESQUISA E

DESENVOLVIMENTO EM DESIGN, 12., 2016, São Paulo. Anais [...] São Paulo: Blucher, 2016. v. 9, n. 2, p. 1.280-1.292.

BARCELLOS, E. et al. De Redig ao P\&D: a trajetória da abordagem da Antropologia no Design. In: CONFERÊNCIA INTERNACIONAL PARA A INTEGRAÇÃO DO DESIGN, ENGENHARIA E ADMINISTRAÇÃO PARA INOVAÇÃO-IDEMI, 4., 2015, Florianópolis. Anais [...]. Florianópolis: UDESC, 2015. p. 527-540. Disponível em:

https://www.researchgate.net/publication/282673132_DE_REDIG_AO_PD_A_TRAJETORIA _DA_ABORDAGEM_DA_ANTROPOLOGIA_NO_DESIGN. Acesso em: 11 mai. 2017.

BENDER, W. N. Aprendizagem baseada em projetos: educação diferenciada para o século XXI. Tradução: Fernando Siqueira Rodrigues. Porto Alegre: Penso Editora, 2014. E-book. Disponível em: https://books.google.com.br/books?hl=pt-BR\&lr=\&id=mBazCAAAQBAJ\&oi=fnd\&pg=PA1\&dq=apren dizagem+baseada+em+projetos\&ots=AIYwBRfVI1\&sig=G7H_HAoUW-FyiCK3KyRUWBFHiv4\#v=onep age\& $q=a p r e n d i z a g e m \% 20$ baseada\%20em\%20projetos\&f=false. Acesso em: 26 jun. 2018 
BENJAMIM, W. Magia e técnica, arte e política: ensaios sobre literatura e história da cultura. São Paulo: Brasiliense, 2012.

BERBEL, N. A. N. A problematização e a aprendizagem baseada em problemas: diferentes termos ou diferentes caminhos? Interface - Comunicação, Saúde, Educação, Botucatu, v. 2, n. 2, p. 139154, fev. 1998. Disponível em: http://www.scielo.br/scielo.php?script=sci_arttext\&pi d=S1414$32831998000100008 \&$ Ing=en\&nrm=iso. Acesso em: 26 jun. 2018.

BONINI, L. A.; SBRAGIA, R. O modelo do Design Thinking como indutor da Inovação nas Empresas: um estudo empírico. Revista de Gestão de Projetos - GeP, São Paulo, v. 1, n. 1., p. 3-25, jan./jun. 2011. Disponível em: http://www.revistagep.org/ojs/index.php/gep/article/view/36. Acesso em: 25 mar 2017.

BORGES, M. C. et al. Aprendizado baseado em problemas. Medicina, Ribeirão Preto, v. 47, n. 3, p. 301-307, 2014. Disponível em: http://revista.fmrp.usp.br/2014/vol47n3/8_Aprendizado-baseadoem-problemas.pdf. Acesso em: 10 out. 2018.

BOROCHOVICIUS, E.; TORTELLA, J. C. B. Aprendizagem Baseada em Problemas: um método de ensino-aprendizagem e suas práticas educativas. Ensaio: Avaliação e Políticas Públicas em Educação, Rio de Janeiro, v. 22, n. 83, p. 263-294, jun. 2014. Disponível em: http://www.scielo.br/scielo.php?script=sci_arttext\&pid=S0104-40362014000200002\&lng= en\&nrm=iso. Acesso em: 26 jun. 2018.

BRAIT, L. F. R. et al. A relação professor/aluno no processo de ensino e aprendizagem. Itinerarius Reflectionis, Jataí, v. 6, n. 1, set. 2010. Disponível em: https://www.revistas.ufg.br/rir/article/view/40868/20863. Acesso em: 10 out. 2018.

BRASIL. [Constituição (1988)]. Constituição da República Federativa do Brasil: promulgada em 5 de outubro de 1988. Brasília, DF: Presidência da República, [1988]. Disponível em:

http://www.planalto.gov.br/ccivil_03/constituicao/constituicaocompilado.htm. Acesso em: 02 fev. 2019.

BRASIL. Lei no 9.394, de 20 de dezembro de 1996. Estabelece as diretrizes e bases da educação nacional. Brasília, DF: Presidência da República, [1996]. Disponível em:

https://www2.senado.leg.br/bdsf/bitstream/handle/id/70320/65.pdf. Acesso em: 31 mar. 2018.

BRASIL. Ministério da Educação. Qual a diferença entre faculdades, centros universitários e universidades? [Brasília], 2018. Portal Ministério da Educação. Disponível em: http://portal.mec.gov.br/pec-g/127-perguntas-frequentes-911936531/educacao-superior399764090/116-qual-e-a-diferenca-entre-faculdades-centros-universitarios-e-universidades. Acesso em: 30 mar. 2018.

CHAUÍ, M. Convite à filosofia. São Paulo: Editora Ática, 1995. 440 p. 
CELASCHI, F.; MORAES, D. (org.). Futuro, bem-estar, interdependência: palavras-chave para o design contemporâneo. In: CELASCHI, F.; MORAES, D. (org.) Cadernos de estudos avançados em Design. Barbacena: EdUEMG, 2013. p. 35-60. (Design \& Humaniamo, v. 7). Disponível em: http://eduemg.uemg.br/arquivos/2013\%20\%20CADERNOS\%20DE\%20ESTUDOS\%20AVANCADOS\%20EM\%20DESIGN\%20\%20HUMANISMO\%20(BILINGUI)\%20-\%20VOL.\%207.pdf. Acesso em: 26 jun. 2018.

CORDI, C. et al. Para filosofar. São Paulo: Editora Scipione, 2001.

COUTO, R. M. S. Fragmento do conhecimento ou interdisciplinaridade: ainda um dilema contemporâneo. Revista Faac, Bauru, v. 1, n. 1, p. 11-19, abr./set. 2011. Disponível em: http://www2.faac.unesp.br/revistafaac/index.php/revista/article/view/34/9. Acesso em: 17 abr. 2018.

CUNHA, M. I. Diferentes olhares sobre as práticas pedagógicas no ensino superior: a docência e sua formação. Educação, Porto Alegre, ano XXVII, n. 3, v. 54, p. 525-536, set./dez. 2004. Disponível em: http://revistaseletronicas.pucrs.br/ojs/index.php/faced/article/download/397/294. Acesso em: 26 jun. 2018.

DE LOS RIOS, I. et al. Project-based learning in engineering higher education: two decades of teaching competences in real environments. Procedia Socialand Behavioral Sciences, Madrid, v. 2, n. 2, p. 1.368-1.378, 2010. Disponível em:

https://www.sciencedirect.com/science/article/pii/S1877042810002429. Acesso em: 17 out. 2018.

EPLEY, N.; TANNENBAUM, D. Treating ethics as a design problem. Behavioral science \& policy, v. 3, n. 2, p. 73-84, 2007. Disponível em: https://behavioralpolicy.org/articles/treating-ethics-as-adesign-problem/. Acesso em: 18 abr. 2020.

FRIEDMAN, B.; KAHN, P. H. Human values, ethics and design. In: SEARS, A.; JACKO, J. A. (org.). The human computer interaction handbook: fundamentals, envolving Technologies and emerging applications. 3. ed. Boca Raton: CRC Press Taylor \& Francis Group, 2003. p. 1178-1197.

GARCEZ, L. V. M.; RIBEIRO, P. P. A.; PEREIRA, J. A. A importância do usuário na metodologia de projeto em design. In: CONGRESSO BRASILEIRO DE PESQUISA E DESENVOLVIMENTO EM DESIGN, 12., 2016, São Paulo. Anais [...]. São Paulo: Blucher, 2016. v. 2, n. 9, p. 1465-1476.

KUBO, O. M.; BOTOMÉ, S. P. Ensino-aprendizagem: uma interação entre dois processos comportamentais. Interação em Psicologia, Curitiba, v. 5, dez. 2001. Disponível em: https://revistas.ufpr.br/psicologia/article/view/3321/2665. Acesso em: 24 mai. 2018.

KULPA, C. C.; PINHEIRO, E. T.; SILVA, R. P. A influência das cores na usabilidade de interfaces através do design centrado no comportamento cultural do usuário. Perspectivas em Gestão e 
Conhecimento. João Pessoa, v. 1, n. especial, p. 119-136, out. 2011. Disponível em: http://www.periodicos.ufpb.br/index.php/pgc/article/view/10795/6086. Acesso em: 10 out. 2018.

LANA, S. A complexidade dos métodos em design. In: MORAES, D.; DIAS, R. A.; SALES, R. B. C. (org.). Cadernos de estudos avançados em Design. Barbacena: EdUEMG, 2011. p. 53-65 (Método, v. 5). Disponível em: http://eduemg.uemg.br/images/livros-pdf/catalogo2011/2011_CADERNOS_DE_ESTUDOS_AVANCADOS_EM_DESIGN_METODO_BILINGUI_VOL_5.pdf. Acesso em: 26 jun. 2018.

LIBÂNEO, J. C. Pedagogia e Pedagogos para quê? São Paulo: Editora Cortez, 2002. 208 p. Disponível em: https://pt.scribd.com/document/339046602/Livro-Pedagogia-e-pedagogos-para-que-JoseCarlos-Libaneo-pdf. Acesso em: 22 mai. 2018.

LUCCHESI, M. A. S. O ensino superior e a influência do modelo francês. In: COLÓQUIO INTERNACIONAL SOBRE GESTÃO UNIVERSITÁRIA NA AMÉRICA DO SUL, 11., Florianópolis, 2011. Anais [...]. Florianópolis: UFSC, 2011. p. 1-14. Disponível em: http://repositorio.ufsc.br/xmlui/handle/123456789/29534. Acesso em: 31 mar. 2018.

MAIOCCHI, M.; PILLAN, M. Design emocional (ou simplesmente design?). In: MORAES, D.; DIAS, R. A. (org.). Cadernos de estudos avançados em Design. Barbacena: EdUEMG, 2013, p. 25-42. (Emoção, v. 8). Disponível em: http://eduemg.uemg.br/images/livros-pdf/catalogo2013/2013_CADERNOS_DE_ESTUDOS_AVANCADOS_EM_DESIGN_EMOCAO_BILINGUI_VOL_8.pdf. Acesso em: 26 jun. 2018.

MAYERNYIK, M. A.; OLIVEIRA, F. A. G. O cuidado empático: contribuições para a ética e sua interface com a educação moral na formação em saúde. Revista Brasileira de Educação Médica, Rio de Janeiro, v. 40, n. 1, p. 11-20, jan./mar. 2016. Disponível em: http://www.scielo.br/scielo.php?script=sci_arttext\&pid=S0100-55022016000100011. Acesso em: 18 abr. 2020.

MORAES, D. Metaprojeto como modelo projetual. In: MORAES, D.; DIAS, R. A; SALES, R. B. C. (org.). Cadernos de estudos avançados em Design. Barbacena: EdUEMG, 2011, p. 35-51. (Método, v. 5) Disponível em: http://eduemg.uemg.br/images/livros-pdf/catalogo-

2011/2011_CADERNOS_DE_ESTUDOS_AVANCADOS_EM_DESIGN_METODO_BILINGUI_VOL_5.pdf. Acesso em: 26 jun. 2018.

MORÁN, J. Mudando a educação com metodologias ativas. In: SOUZA, C. A.; MORALES, O. E. T. (org). Convergências Midiáticas, Educação e Cidadania: aproximações jovens. 2015. p. 15-33 (Mídias contemporâneas, v.2) Disponível em: http://www2.eca.usp.br/moran/wpcontent/uploads/2013/12/mudando_moran.pdf. Acesso em: 26 jun. 2018.

NAVES, E. T. Fazer-Saber: reflexões sobre a função acadêmica da extensão universitária. Em Extensão, Uberlândia, v. 14, n. 1, p. 9 - 29, jan. - jun. 2015. Disponível em: http://www.seer.ufu.br/index.php/revextensao/article/view/28113. Acesso em: 30 mar. 2018. 
NEVES, E. P. et al. Panorama da pesquisa em design no Brasil: a contribuição dos Programas de PósGraduação em Design nas pesquisas científicas e no desenvolvimento da área. Arcos Design, Rio de Janeiro, v. 8, n. 1, p. 78-95, jun. 2014. Disponível em: http://www.e-

publicacoes.uerj.br/index.php/arcosdesign/article/view/13927. Acesso em: 11 out. 2018.

NOTAS de aula da disciplina Didática do Ensino Superior. Claretiano Rede de Educação, 2018. Disponível em: https://claretiano.edu.br/. Acesso em: 08 abr. 2019.

OLIVEIRA, R. O Trabalho de Antropólogo. 2. ed. rev. Brasília: Paralelo 15, 2000.

PORTUGAL, C.; COUTO, R. Design em situações de ensino-aprendizagem. Estudos em Design, Portugal, v. 18, n. 1, p. 1-22, 2010. Disponível em:

https://estudosemdesign.emnuvens.com.br/design/article/view/42/39. Acesso em: 17 abr. 2018.

RIVAS, N. P. P.; CONTE, K. M.; AGUILAR, G. M. Novos espaços formativos na universidade: desafios e perspectivas para a docência superior. In: CONGRESSO ESTADUAL PAULISTA SOBRE FORMAÇÃO DE EDUCADORES, 9., São Paulo. Anais [...]. São Paulo: UNESP, 2007. p. 2-11 Disponível em: http://www.unesp.br/prograd/ixcepfe/Arquivos\%202007/10eixo_relatos.pdf. Acesso em: 26 jun. 2018.

ROCHA, C. B.; CORREIA, G. C. S. Ética na docência do ensino superior. Revista Educare. Montes Claros, v. 2, p. 1-8, 2006. Disponível em:

https://edisciplinas.usp.br/pluginfile.php/2234046/mod_resource/content/1/etica-carlagenilce.pdf. Acesso em: 18 abr. 2020.

SAVIANI, D. A expansão do ensino superior no Brasil: mudanças e continuidades. Poíesis Pedagógica, Goiás, v. 8, n. 2, p. 4-17, abr. 2011. Disponível em:

https://revistas.ufg.br/poiesis/article/view/14035. Acesso em: 28 mar. 2018.

SAVIANI, D. O futuro da universidade entre o possível e o desejável. Revista Estudos Avançados da Unicamp online, Campinas, set. 2009. Artigos do CEAv. Disponível em:

http://www.gr.unicamp.br/ceav/revista/content/pdf/O_futuro_da_universidade_Dermeval_Savian i.pdf. Acesso em: 31 mar. 2018.

VASCONCELOS, C.; PRAIA, J. F.; ALMEIDA, L. S. Teorias de aprendizagem e o ensino/aprendizagem das ciências: da instrução à aprendizagem. Psicologia Escolar e Educacional, Campinas, v. 7, n. 1, p. 11-19, jun. 2003. Disponível em: https://doi.org/10.1590/S1413-85572003000100002. Acesso em: 10 out. 2018. 